\title{
Reviews
}

\section{Phenylketonuria in Britain: genetic analysis gives a historical perspective of the disorder but will it predict the future for affected individuals?}

\author{
L A Tyfield
}

Most hyperphenylalaninaemia is caused by a loss of the activity of the enzyme phenylalanine hydroxylase (PAH). It has been known for some time that there are varying degrees of hyperphenylalaninaemia (HPA) and at its most severe it results in phenylketonuria (PKU), a condition that requires strict dietary management if the severe neurological sequelae naturally associated with the untreated condition are to be prevented. At its mildest, it results in a non-PKU hyperphenylalaninaemia (non-PKU HPA), which does not require dietary restriction to maintain concentrations within limits that will ensure normal physical, neurological, and cognitive development. Between these two extremes there is a whole range of phenotypic variability, most of which is related to allelic variation at the PAH locus. (Disorders of hydroxylation resulting from defective enzymes in the synthesis and regeneration of the cofactor pathway will not be considered here.)

PKU is one of the inborn errors of metabolism and the genetics of the disorder are straightforward-they follow a typical Mendelian autosomal recessive pattern of inheritance. Until recently, this was relevant usually in relation to the risk of a couple, known to be carriers, of having another affected child ( 1 in 4 ) or to the chance of a sibling of an affected child being a carrier ( 2 in 3 ) and then, to the population risk of a partner with no known family history carrying a mutant gene. With the arrival of the age of molecular genetics and the cloning of the PAH gene, ${ }^{1}$ the genetics of PKU have taken on a different significance and extensive examination of the gene over the past decade has unearthed a plethora of information that is relevant both to the severity of the disease in individual families and to the history of the gene in various populations.

Molecular Genetics Unit, The Lewis Laboratories, Southmead Hospital, Bristol BS10 5NB

Accepted for publication 24 April 1997 somes (fig 1). Originally, a diallelic haplotype system incorporating seven restriction fragment length polymorphic markers (RFLPs) ${ }^{3}$ was used to describe the genetic background of this locus. This has been expanded to include a multi-allelic short tandem repeat system (STR), ${ }^{4}$ a multi-allelic HindIII system of variable number of tandem repeats (VNTR), ${ }^{5}$ and several silent polymorphisms within the coding region of the gene. The latter arise from a substitution, usually in the last base of a codon, with no resulting change in the amino acid sequence of the protein. In theory, the polymorphic systems could manifest more than 6000 different haplotypes, but in reality, only a small number of these have been described on contemporary chromosomes. In recent years, there has been a decline in describing the diallelic haplotypes, probably because of the large amount of work involved. Frequently, an individual is heterozygous at more than one polymorphic site and, therefore, DNA is often needed from two or three family members if complete haplotypes are to be constructed. In addition, efforts have tended to concentrate on defining the genetic background of mutant rather than normal chromosomes. Nevertheless, the high degree of heterozygosity at the PAH locus is extremely useful for prenatal diagnosis and carrier testing whenever these are required.

\section{PAH mutations}

For any genetic disorder (except sickle cell disease) genetic heterogeneity is the rule rather than the exception. To the end of February 1997, more than 310 mutations were reported to the PAH Mutation Analysis Consortium database. ${ }^{6}$ (The curators of the PKU Mutations Analysis Consortium are at the Montreal Children's Hospital, Montreal, Quebec, Canada. The database is accessible on the Internet (http://www.mcgill.ca/pahdb); in February 1997 there were 91 members of the consortium in 29 countries. More than 5000 PKU chromosomes have been studied worldwide.) Most mutations (almost $60 \%$ ) are missense mutations, ${ }^{7}$ which cause an amino acid change in the PAH protein. In addition, there are nonsense mutations that introduce a premature
The gene is on the long arm of chromosome 12 in the band region $\mathrm{q} 22-\mathrm{q} 24.1 .^{2}$ It has 13 coding regions (exons) within $90 \mathrm{~kb}$ of DNA and the transcribed mRNA is $\sim 2.4 \mathrm{~kb}$ long. The PAH region of chromosome 12 is rich in polymorphic markers and these can be used to describe both mutant and normal chromo- 
Table 1 Evidence of hypermutability at codons involving $C_{p} G$ dinucleotides at the PAH gene $^{8}$

\begin{tabular}{|c|c|c|c|}
\hline Codons & Sequence change & Mutation & Haplotype associations \\
\hline 111 & CGA $\rightarrow$ TGA & R111X & $1,4,5,28$ \\
\hline 158 & $\begin{array}{l}\text { CGG } \rightarrow \mathrm{CAG}^{\star} \\
\mathrm{CGG} \rightarrow \mathrm{TGG}\end{array}$ & $\begin{array}{l}\mathrm{R} 158 \mathrm{Q} \\
\mathrm{R} 158 \mathrm{~W}\end{array}$ & $1,2,4,7,16,28$ \\
\hline 241 & $\mathrm{CGC} \rightarrow \mathrm{CAC}^{\star}$ & $\mathrm{R} 241 \mathrm{H}$ & 1,5 \\
\hline & $\mathrm{CGC} \rightarrow \mathrm{TGC}$ & R241C & 1. \\
\hline 243 & $\begin{array}{l}\mathrm{CGA} \rightarrow \mathrm{CAA}^{\star} \\
\mathrm{CGA} \rightarrow \mathrm{TGA}\end{array}$ & $\begin{array}{l}\text { R243Q } \\
\text { R243X }\end{array}$ & $\begin{array}{l}4,7,9 \\
4\end{array}$ \\
\hline 252 & CGG $\rightarrow$ CAG $^{\star}$ & R252Q & 1 \\
\hline 261 & $\begin{aligned} \mathrm{CGG} \rightarrow \mathrm{TGG} \\
\mathrm{CGA} \rightarrow \mathrm{CAA}^{\star} \\
\mathrm{CGA} \rightarrow \mathrm{TGA}^{2}\end{aligned}$ & $\begin{array}{l}\text { R252W } \\
\text { R261Q } \\
\text { R261X }\end{array}$ & $\begin{array}{l}1,6,7,8,42,69 \\
1,2,4,22,24,28 \\
2,3,4\end{array}$ \\
\hline 280 & GAA $\rightarrow$ AAA $^{\star} \dagger$ & E280K & $1,2,4,16,28$ \\
\hline 281 & $\mathrm{CCg} \rightarrow \mathrm{CTg} \ddagger$ & P281L & 1,4 \\
\hline 297 & $\mathrm{CGC} \rightarrow \mathrm{CAC}^{\star}$ & $\mathrm{R} 297 \mathrm{H}$ & \\
\hline 388 & $\begin{array}{l}\text { CGC } \rightarrow \text { TGC } \\
\text { GTG } \rightarrow \text { ATG }^{\star}+\end{array}$ & $\begin{array}{l}\text { R297C } \\
\text { V388M }\end{array}$ & 1,4 \\
\hline 408 & $\begin{array}{l}\mathrm{CGG} \rightarrow \mathrm{TGG}^{\star} \\
\mathrm{CGG} \rightarrow \mathrm{CAG}^{\star}\end{array}$ & $\begin{array}{l}\text { R408W } \\
\text { R408Q }\end{array}$ & $\begin{array}{l}1,2,4,5,13,34,41,44 \\
4,12\end{array}$ \\
\hline
\end{tabular}

The table includes only those codons that carry multiple mutations and/or multiple haplotype associations of individual mutations.

*The CpG dinucleotide and the mutated methylated cytosine is on the atemplate strand; hence the observed base change on the template strand is a $\mathrm{G} \rightarrow \mathrm{A}$ transition.

tThe CpG dinucleotide spans two codons (in the case of E280K the sequence is CCC GAA at codons 279 and 280 , respectively). The mutation is on the atemplate strand and thus the observed change is a $\mathbf{G} \rightarrow$ A transition on the template strand.

$¥$ The lower case indicates that this is the first nucleotide of the subsequent intron.

stop codon, deletions and insertions (some of which alter the reading frame), and splice site mutations which alter $\mathrm{mRNA}$ processing. The distribution of the numbers of mutations along the gene are also shown in fig 1 .

Several mutations occur at $\mathrm{CpG}$ dinucleotides. These are hypermutable sites in the genome and the hypermutability usually is related to the methylation status of the cytosine residue. Spontaneous deamination of cytosine, methylated at the $5^{\prime}$ ring position, will change cytosine to thymine (with a guanine to adenine transition on the corresponding strand). In the $\mathrm{PAH}$ gene, 24 codons involve CpG sites. $^{8}$ Although mutations have not been reported at seven of them, 24 mutations involving the $\mathrm{CpG}$ dinucleotides have been reported at the remaining 17. Often, their hypermutability is observed either by the appearance of different mutations within the same codon or by the appearance of the same mutation on multiple haplotype backgrounds (table 1). Information about the relative frequencies of mutations on different haplotypes within different popula- 3 tions can be useful in defining the relative age으 and geographical origin of that mutation.

\section{Population distributions of mutations}

The PAH gene has been studied extensively in many populations throughout the world. ${ }^{7}$ Glo-흠 bally, R408W (a substitution of tryptophan for $\frac{\overline{\bar{T}}}{7}$ arginine at amino acid position 408 of the PAH ${ }_{\Omega}$ protein) is the most common mutation, accounting for $30.4 \%$ of mutant chromo- somes, and it has been reported on eight differ- ent diallelic haplotype backgrounds ${ }^{6}$ (table 1). $\vec{\omega}$ In addition, in many populations of northern Europe R408W is the most common mutation? and here it is found principally on haplotypes 1 \% and $2 .^{9-13}$ The haplotype 2 association is more ${ }^{+}$ prevalent in north-east Europe and there $\vec{\sigma}$ appears to be a centre of diffusion for this 0 association in Belarus. ${ }^{14}$ In north-west Europe ${ }^{\supset}$ the mutation is associated predominantly with haplotype 1 and the centre of diffusion for thiso association is Ireland. The two haplotype patterns are similar in that the six polymorphic $-\vec{\theta}$ sites from the $5^{\prime}$ end of the gene are identical ${ }^{6} \mathrm{e}$ but they differ at the HindIII and EcoRV sites at the $3^{\prime}$ end. It is possible that the mutationo arose only once and was transferred by as recombination event from one haplotype to the other. However, the mutation occurs at one of the hypermutable sites in the gene and detailed examination of the STR and VNTR sequenceso of haplotypes 1 and 2 , on both mutant and $\vec{J}$ normal chromosomes, indicates that almost certainly it arose as two independent events. ${ }^{15}$

In the British Isles, three mutations are mosto prevalent: R408W in exon 12; IVS12nt1, 윽 which is a splice site mutation at the exon $/ 3$ intron 12 boundary; and I65T, which is in exon응 3. ${ }^{12}$ Together, these account for about $50 \%$ of

A

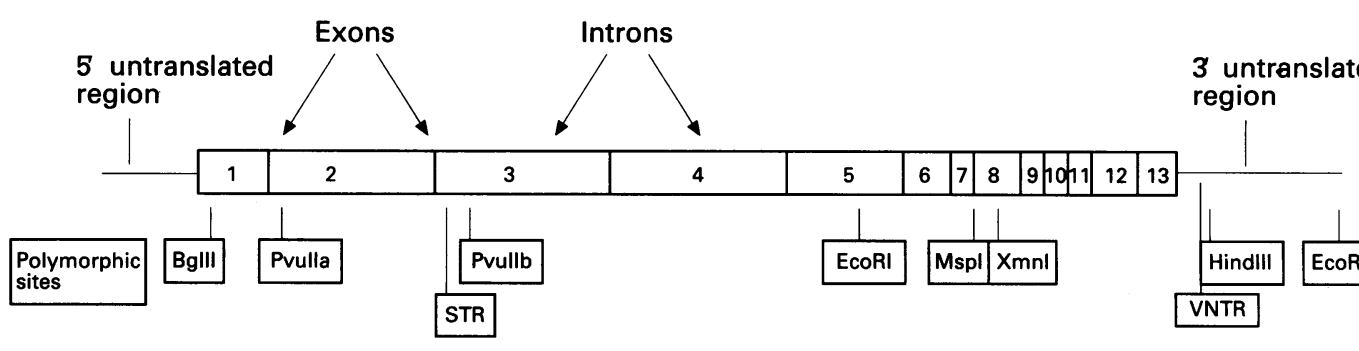

B

\begin{tabular}{|c|c|c|c|c|c|c|c|c|c|c|c|c|}
\hline Exon & 5 UTR & 1 & 2 & 3 & 4 & 5 & 6 & 78 & & 9101112 & 13 & 3 UTR \\
\hline $\begin{array}{l}\text { Number } \\
\text { of mutations }\end{array}$ & - & 6 & 15 & 19 & 11 & 13 & 48 & 5212 & & 12273113 & 1 & - \\
\hline $\begin{array}{l}\text { Splice site } \\
\text { mutations or } \\
\text { polymorphisms }\end{array}$ & 5 & 1 & 7 & 2 & 4 & 5 & & 25 & 3 & $\begin{array}{llll}5 & 4 & 5 & 5\end{array}$ & 51 & 1 \\
\hline
\end{tabular}

Figure 1 (A) Diagram of the PAH gene. Exons are represented as thin vertical lines; introns are the spaces between them. Relative positions of the diallelic polymorphic sites and the multi-allelic STR and VNTR polymorphic systems are shown. (B) Numbers of mutations that have been reported within the exons of the gene and as splice site mutations or mutations/polymorphisms within introns and 5' and 3' untranslated regions of the gene. Data taken from reference 7. 


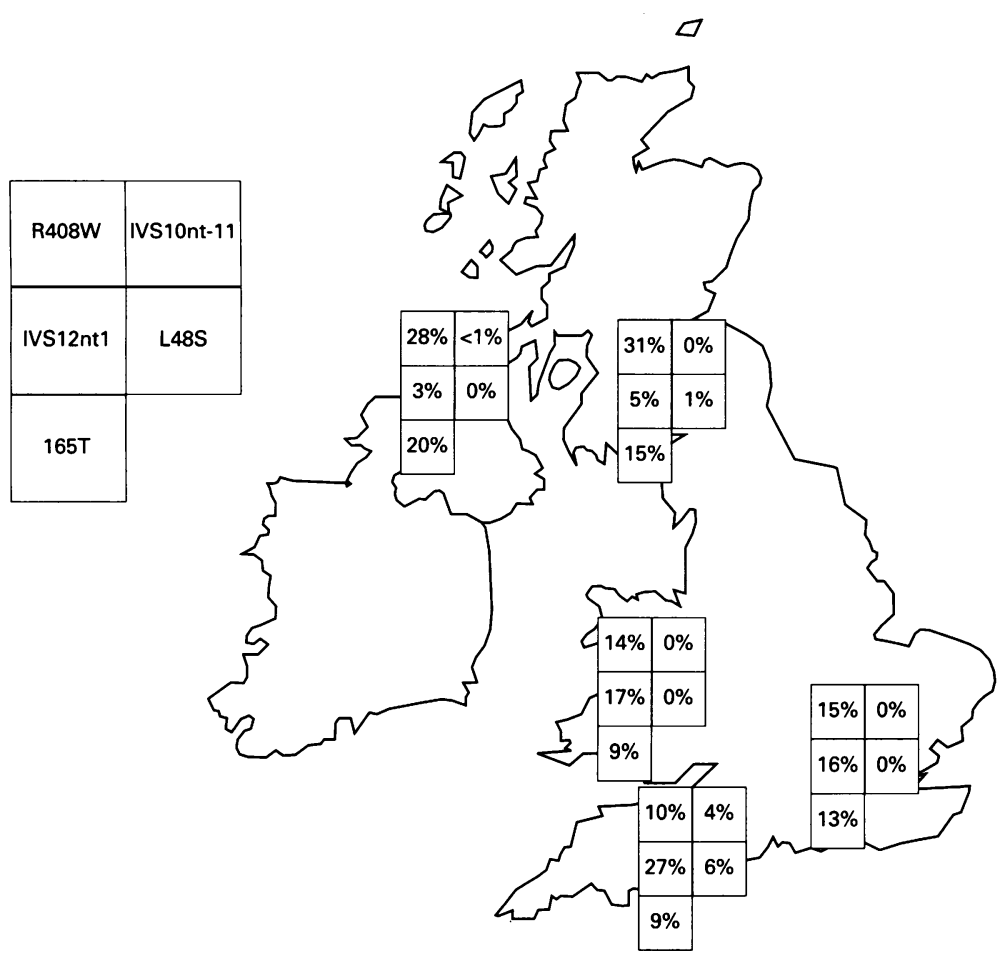

Figure 2 Relative frequencies of some of the more common mutations seen in different geographical areas of the British Isles. Those for western Scotland, south Wales, south-west England, and London are taken from Tyfield et $a^{l^{2}}$; those for Northern Ireland are taken from Zschocke et al. ${ }^{9}$ lished the Danish kingdom over a large part of central Britain. ${ }^{19}$ Alternatively, the mutation could have been introduced first by the Angles, Saxons, or Jutes who settled in much of east and south Britain during the 5th century AD. In either case, one would anticipate a high relative frequency of IVS12nt+1 in the eastern coastal regions of England. The fact that the mutation is associated almost exclusively with a diallelic haplotype 3 background suggests that it is relatively new.

The relative frequencies of these mutations in London and south Wales, where samples have come principally from in and around Cardiff, are almost identical ${ }^{12}$ (fig 2). The diverse grandparental origin of many PKU individuals in south Wales suggests that the similarities between the Welsh and London samples are more likely to reflect the heterogeneity that is seen in the populations of two large capital cities, rather than any similarity in the indigenous populations of the two areas.

The distribution of the I65T mutation is interesting because it is quite common in the populations of the United Kingdom and Spain, as well as in areas of the world that have been inhabited over the last three centuries by immigrants of Anglo-Celtic and Spanish origin. ${ }^{12}{ }^{20-23}$ It is relatively rare in other European populations. ${ }^{7}$ Owing to its high frequency in Ireland, it has been proposed to be "Celtic" in origin, but its association with the greatest numbers of haplotypes (encompassing diallelic, STR, and VNTR polymorphisms) suggests that it is one of the oldest at the PAH locus and probably predates the arrival of the Celts in Ireland. A hypermutable sequence is not involved.

Another splice site mutation, IVS10nt-11, is most common in populations of southern Europe, including those of Mediterranean and Arabic origin..$^{21-26}$ It occurs with the highest frequency in Turkey, ${ }^{26}$ and an east-west gradient in its relative frequency in south European populations has led to the proposal that it originated in the Middle East and spread west and north by the migration of Neolithic farmers. ${ }^{27}$ In the British Isles, this mutation and another, which is common in south European populations (L48S), appear almost exclusively in south-west England, where together they account for $10 \%$ of mutant chromosomes. ${ }^{12}$ This is highly significant $(p<0.001)$ and although they may have been brought to south-west England through the Megalithic builders from Hibernia, the association of each with multiple genetic backgrounds suggests that there were multiple origins. The association of IVS10nt-11 with many haplotypes suggests also that it is very old.

\section{Rare mutations}

In most population studies where mutation ascertainment is virtually complete, five or six mutations account for between $30 \%$ and $50 \%$ of mutant alleles and the remainder are usually multiple and varied. In the PKU population of the British Isles, for example, 72 different mutations have been identified on 500 independent chromosomes from western Scotland, 
south Wales, south-west and south-east England. Fifty five mutations $(76 \%)$ have been found on fewer than $1 \%$ of chromosomes and 35 (almost half) were found only once. Of these, 15 mutations had not been reported previously to the Mutation Analysis Consortium database. Eleven mutations were found on only two alleles in apparently unrelated individuals (some in the same geographical area, others in a different area). Where genealogical evidence is lost, detailed examination of the haplotype background on which the mutations are found may provide evidence of an identity by descent. In this regard, sometimes one of the more common mutations has been found in a particularly unusual haplotype association. I65T, for example, which occurs almost entirely on a haplotype 9 in the British Isles, was found on a very rare haplotype 49 background. This mutation could have arisen through a recombination between a mutant haplotype 9 and a normal haplotype 4 which is common in western England. ${ }^{28}$ Its appearance in the same unusual association on a single allele in an Australian study ${ }^{23}$ almost certainly represents an identity by descent, particularly in view of the Anglo-Celtic origin of many Australian settlers over the last century.

It is worth mentioning that PKU is very rare among people of African origin. It has been proposed $^{29}$ that mutations at the PAH locus arose after the original migration and diaspora out of Africa over 100000 years ago. Furthermore, it is suggested that the mutations now found in black individuals will have been introduced into the families through ancestral matings with non-blacks. In our own study only four of almost 600 mutant alleles that we have examined in the British Isles are from black children. The parents of one child are both Afro-Caribbean and two children are of mixed race (Afro-Caribbean/Welsh and AfroCaribbean/Jewish). Although the two children in whom both mutations have been identified

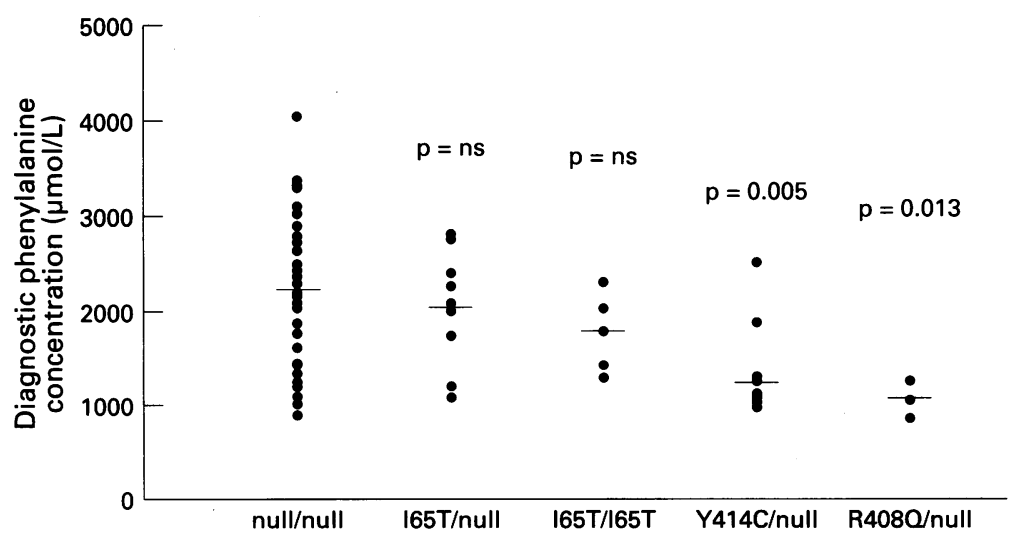

Figure 3 Diagnostic phenylalanine concentrations in PKU infants carrying combinations of mutations with varying degrees of $P A H$ enzyme activity based on in vitro expression analysis. "Null" means zero enzyme activity. The associated activities of the other mutations are: $165 T, 26 \%{ }^{31} ; Y 414 C, \sim 50 \%{ }^{32} ; R 408 Q, 55 \% .^{33}$ Thus, individuals homozygous for I65T would be expected to have about the same residual activity as those carrying Y414C/null and R408Q/null mutations. Median values for each group are shown (horizontal bar). Kruskal-Wallis non-parametric statistical analysis showed that there was no statistically significant difference between those infants carrying two null mutations and those carrying either I65T/null (13\% activity) or those homozygous for $165 T$ (26\% activity). It is important to mention, however, that three of the children with I65T/I65T were siblings. The difference between the null group and those carrying Y414C/null (25\% activity) and those with $R 408 Q /$ null $\left(\sim 26 \%\right.$ activity) were statistically significant. ${ }^{34}$ both carry one that is common in northern Europe (I65T and R408W), the mutation on the other allele is very rare $(\mathrm{P} 122 \mathrm{Q}$ and $\mathrm{R} 252 \mathrm{Q})$. Although $\mathrm{R} 252 \mathrm{Q}$ has been reported in other populations within Europe, China, and 3 the United States, ${ }^{7} \mathrm{P} 122 \mathrm{Q}$, associated with 으 extremely rare but related haplotypes, has been reported on only two additional alleles in Spanish individuals. ${ }^{21}$

\section{Carrier testing}

In most countries of the developed world, $\frac{\bar{D}}{\bar{D}}$ population screening for PKU is undertaken in $\vec{\nabla}$ the neonatal period. Almost complete ascertainment of affected individuals enables a true incidence of PKU to be determined in any $\vec{\circ}$ population. The disorder is rare in Japan and $\overrightarrow{\vec{\omega}}$ virtually unheard of in Finland. In other Euro- $\stackrel{\omega}{\circ}$ pean countries and those of North America the 3 incidence is generally about one in $10000 \mathrm{cr}$ individuals. A finer deliniation of populations shows that within relatively small geographical $\vec{\overrightarrow{ }}$ distances there can be relatively large differ- 6 ences in incidence. Within the British Isles 오 alone, for example, hyperphenylalaninaemia is $\rightarrow$ found in approximately one in 12000 newborn infants in south-west England; in south Wales, $\frac{\vec{e}}{\infty}$ it is approximately one in 10000 ; in western Scotland the figure is nearer one in 7500 ; in $\vec{\theta}$ Northern Ireland it is approximately one in. 4500. Assuming Hardy-Weinberg equilibrium (where there is the possibility of only two alleles in the population, "normal" and "mutant", $p$ is the frequency of the normal gene at the

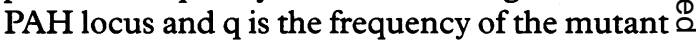
allele) in all of these populations $\vec{\circ}$ $\left(p^{2}+2 p q+q^{2}=1\right)$ the carrier frequency (2pq) will vary from one in 35 (in Northern Ireland) to one in 55 (in south-west England).

In this regard, carrier testing for a mutation at the $\mathrm{PAH}$ gene can be undertaken only for: individuals, who are direct relatives of an 3 . affected family member. If the mutation has $\delta$ been identified, this is a relatively straightforward procedure but if not, gene tracking using 음 any of the polymorphic markers can be under- $\rightarrow$ taken to establish whether the consultand has an allele in common with the affected indi- N vidual. When known carriers, or known PKU individuals, ask for the carrier status of their partners to be determined, biochemical analy- $\omega$ sis is still the first test to offer. A phenylalanine:?

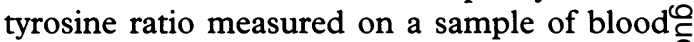
taken at midday after an overnight fast will determine carrier status. If this test shows that the individual is likely to be a carrier, molecular genetic analysis can be undertaken. How- $\stackrel{\mathbb{D}}{\circ}$ ever, as there are over 310 mutations character- $\mathbb{\mathbb { D }}$ ised, a definitive answer is not always guaranteed.

\section{Genotype/phenotype correlations}

In vitro expression analysis shows that each mutation has a particular quantitative effect on enzyme activity. ${ }^{30}$ Some mutations are found to be associated with a complete loss of enzyme activity, whereas others are associated with residual activity, ranging from $5 \%$ to $70 \% .^{70-34}$ It can be anticipated that various combinations 
of mutations would result in a full spectrum of biochemical phenotypes, ranging from classic PKU (requiring strict dietary management) to mild non-PKU HPA (in which dietary restriction of phenylalanine is not necessary).

Some mutations (R297P, A322G, T380M, $\mathrm{D} 425 \mathrm{~N}$, as a few examples) appear to be associated only with a non-PKU $\mathrm{HPA}^{7}$; when they occur in combination with a null mutation, the diagnostic phenylalanine concentrations in these individuals and phenylalanine concentrations on an unrestricted intake are never above $\sim 450 \mu \mathrm{mol} / \mathrm{l}$. At the other end of the spectrum, it is probably safe to say that the highest diagnostic phenylalanine concentrations are usually found in infants, whether breast or formula fed, who have the lowest associated PAH activity. ${ }^{35}$ However, diagnostic concentrations in infants carrying two null mutations can range from $\sim 1000$ to $>3000 \mu \mathrm{mol} / 1$ and there is a large overlap with those carrying at least one mutation which is believed to be associated with residual enzyme activity ${ }^{35}$ (fig 3).

This also applies to the severity of the disorder as determined by the degree of dietary phenylalanine intake, the relative ease of dietary management or, ultimately, the clinical outcome. Generally, those children with a complete lack of PAH activity tend to have the greatest dietary phenylalanine restriction at all stages of development but, once again, there are large overlaps between those with two null mutations and individuals carrying a less deleterious one (unpublished results). Thus, for any individual phenylketonuric infant, a lower diagnostic phenylalanine concentration in the neonatal period will not necessarily imply residual enzyme activity and, therefore, predict a less severe biochemical phenotype.

The fact that additonal genetic, constitutional, and envionmental factors contribute to the overall phenotype is also manifest by the large variation in the intellectual outcome of untreated subjects with the same genotype, both within and between families. ${ }^{36-38}$ The precise biological mechanisms by which phenotypic variation occurs are not known, but it is certain that the contributing factors are multiple and varied. Treacey et $a{ }^{39}$ for example, have shown that although there is an identical hydroxylation of phenylalanine to tyrosine in affected siblings with the same genotype, there can be variation in phenylalanine use through additional pathways involved in phenylalanine homeostasis.

Therefore, it is clear that although in vitro expression systems are extremely important and useful laboratory tools for establishing the more proximate effects of a particular mutation such as the effects on mRNA synthesis, protein synthesis, or enzyme activity, they allow only a relative order of severity of various mutations to be established. The more ultimate effects in affected subjects (ease of dietary biochemical control or clinical outcome in treated or untreated patients) must take into account additional complementary influences that are involved both in phenylalanine metabolism in particular and neurophysiological development in general. Ultimately, a simple correlation may not always be apparent between genotype at the PAH gene and clinical phenotype.

Results of the PAH gene analysis presented here were part of a multicentre study in the British Isles. We are deeply indebted to many clinicians throughout England, Scotland, and Wales who sent us samples from their PKU patients and to the patients themselves and their families who participated so willingly in the project. We gratefully acknowledge the generosity of Professor Charles Scriver and Susan Byck who gave us primers for denaturing gradient gel electrophoresis analysis. Mrs Anne Stephenson carried out the genetic analyses in the laboratory at Southson carried out the genetic analyses in the laboratory at South-
mead Hospital and she was supported by a grant from the Wellcome Trust.

1 Robson KJH, Chandra R, MacGillivray RTA, Woo SLC Polysome immunoprecipitation of phenylalanine hydroxylase mRNA from rat liver and cloning of its cDNA. Proc Natl Acad Sci USA 1982;79:4701-5.

2 Kwok SCM, Ledley FD, DiLella AG, Robson KJH, Woo SLC. Nucleotide sequence of a full-length complementary DNA clone and amino acid sequence of human phenylalanine hydroxylase. Biochemistry 1985;24:556-61.

3 DiLella AG, Kwok SCM, Ledley FD, Marvit J, Woo SLC. Molecular structure and polymorphic map of human phenylalanine hydroxylase. Biochemistry 1986;24:743-9.

4 Goltsov AA, Eisensmith RC, Naughton ER, Hin L Goltsov AA, Eisensmith RC, Naughton ER, Hin L,
Chakraborty R, Woo SLC. A single polymorphic STR system in the human phenylalanine hydroxylase gene permits rapid prenatal diagnosis and carrier screening for phenylketonuria. Hum Mol Genet 1993;2:577-81.

5 Goltsov AA, Eisensmith RC, Konecki DS, Lichter-Konecki U, Woo SLC. Associations between mutations and a VNTR in the human phenylalanine hydroxylase gene. $A m \mathcal{F}$ Hum Genet 1992;51:627-36.

6 Nowacki P, Byck S, Prevost L, Scriver CR. PAH Mutation Analysis Consortium databàse update. Nucleic Acids Res 1997;25:139-42.

7 Byck S, Nowacki P, Prevost L, Scriver CR. PAH Mutation Analysis Consortium Newsletter, Winter, 1997.

8 Byck S, Tyfield L, Carter K, Scriver CR. Prediction of multiple hypermutable codons in the human PAH gene: codon 280 contains recurrent mutations in Quebec and other populations. Hum Mut 1997;9:316-21.

9 Zschocke J, Graham CA, Carson DJ, Nevin NC. Phenylketonuria mutation analysis in Northern Ireland: a rapid stepwise approach. Am f Hum Genet 1995;57:1311-17.

10 Kozak L, Kuhrova V, Blazkova M, Romano V, Fajkusova L Dvorakova D, et al. Phenylketonuria mutations and their relation to RFLP haplotypes at the PAH locus in Czech PKU families. Hum Genet 1995;96:472-6.

11 Lillevali H, Ounap K, Metspalu A. Phenylalanine hydroxylase gene mutation R408W is present in $84 \%$ of Estonian phenylketonuria chromosomes. Eur $\mathcal{f}$ Hum Genet 1996;4 296-300.

12 Tyfield LA, Stephenson A, Cockburn F, Harvie A, Bidwell $J \mathrm{~L}$, Wood NAP, et al. Sequence variation at the phenylalanine hydroxylase gene in the British Isles. Am $\mathcal{f}$ Hum lanine hydroxylase gen

13 Michiels L, Francois B, Raus J, Vandevyver C. The identification of 7 new mutations in the phenylalanine hydroxylase gene, associated with hyperphenylalaninaemia in the Belgian population. Hum Mutat 1997. [In press.]

14 Eisensmith RC, Goltsov AA, O'Neill C, Tyfield LA, Schwartz EI, Kuzmin AI, et al. Recurrence of the R408W mutation in the phenylalanine hydroxylase locus in Europeans Am ₹ Hum Genet 1995;56:278-86.

15 Byck S, Morgan K, Tyfield L, Dworniczak B, Scriver CR. Evidence for origin, by recurrent mutation, of the phenylaEvidence for origin, by recurrent mutation, of the phenyla-
lanine hydroxylase R408W mutation on two haplotypes in lanine hydroxylase R408W mutation on two haplotypes in European

16 Sunderland E, Tills D, Bouloux C, Doyl J. Genetic studies in Ireland. In: Roberts DF, Sunderland E, eds. Genetic variation in Britain. London: Taylor \& Francis, 1973:141-60.

17 Eisensmith RC, Woo SLC. Molecular basis of phenylketonuria and related hyperphenylalaninaemias: mutations and polymorphisms in the human phenylalanine hydroxylase gene. Hum Mutat 1992;1:13-23.

18 Guldberg P, Henriksen KF, Guttler F. Molecular analysis of phenylketonuria in Denmark: $99 \%$ of the mutations detected by denaturing gradient gel electrophoresis. Genomics 1993;17:141-6.

19 Roberts DF. The origins of genetic variation in Britain. In: Roberts DF, Sunderland E, eds. Genetic variation in Britain. London: Taylor \& Francis, 1973:1-16

20 Perez B, Desviat LR, DeLucca M, Schmidt B, LoghinGrosso GR, Pires RF, et al. Mutation analysis of phenylketonuria in south Brazil. Hum Mutat 1996;8:262-4.

21 Perez B, Desfiat LR, Ugarte M. Analysis of the phenylalanine hydroxylase gene in the Spanish population: mutation profile and association with intragenic polymormutation profile and association with intragenic

22 Treacey E, Byck S, Clow C, Scriver CR. 'Celtic' phenylketonuria chromosomes found? Evidence in two regions of Quebec province. Eur F Hum Genet 1993;1:2208 .

23 Ramus SJ, Treacey EP, Cotton RGH. Characterization of phenylalanine hydroxylase alleles in untreated phenylke- 
tonuria patients from Victoria, Australia: origin of alleles and haplotypes. Am f Hum Genet 1995;56:1034-41.

24 Guldberg P, Romano V, Ceratto N, Bosco P, Ciuna M, Indelicato $\mathrm{A}$, et al. Mutational spectrum of phenylalanine hydroxylase deficiency in Sicily: implications for diagnis of hyperphenylalaninaemia in Southern Europe. Hum $\mathrm{Mol}$ of hyperphenylalanina

25 Dianzani I, Giannattasio S, de Sanctis L, Alliaudi C, Lattanzio P, Dionisi Vici C, et al. Characterisation of phenylketonuria alleles in the Italian population. Eur $\mathcal{F} \mathrm{Hum}$ Genet 1995;3:294-302.

26 Ozguc M, Erdem H, Yilmaz E, Coskun T, Ayter S, Doonen $\mathrm{O}$, et al. Mutation analysis in Turkish phenylketonuria patients. F Med Genet 1993;30:129-30.

27 Dianzani I, Giannattasio S, de Sanctis L, Marra E, Ponzone A, Camaschella C, et al. Genetic history of phenylketonuria A, Camaschella C, et al. Genetic history of phenylket

28 Tyfield LA, Osborn MJ, King SK, Jones MM, Holton JB. Molecular basis of phenylketonuria in an English population. Dev Brain Dysfunct 1993;6:60-7.

29 Scriver CR, Byck S, Prevost L, Hoang and the PAH Mutation Analysis Consortium. The phenylalanine hydroxylase locus: a marker for the history of phenylketonuria and human genetic diversity. In: Chadwick D, Cardew G, eds. Variation in the human genome. Ciba Foundation Symposium 197. John Wiley \& Sons, 1996:73-96.

30 Okano Y, Eisensmith RC, Guttler F, Lichter-Konecki U, Konecki DS, Trefz FK, et al. Molecular basis of phenotypic heterogeneity in phenylketonuria. N Engl f Med 1991;324 1232-8

31 ' Lyonnet S, Caillaud C, Rey F, Berthelon M, Frezal J, Rey J et al. Molecular genetics of phenylketonuria in Mediterranean countries: a mutation associated with partial phenylalanine hydroxylase deficiency. Am f Hum Genet 1989;44: 511-17.
32 John SWM, Scriver CR, Laframboise R, Rozen R. In vitro and in vivo correlations for $I 65 \mathrm{~T}$ and M1V mutations at the phenylalanine hydroxylase locus. Hum Mutat 1992;1:14753.

33 Okano Y, Eisensmith RC, Dasovich M, Wang T, Guttler F, Woo SLC. A prevalent missense mutation in Northern Europe associated with hyperphenylalaninaemia. Eur $f$ Pediatr 1991;150:347-52.

34 Svensson E, Eisensmith RC, Dworniczak B, von Dbeln U, Hagenfeldt L, Horst J, et al. Two missense mutations causing mild hyperphenylalaninaemia associated with DNA haplotype 12. Hum Mutat 1992;1:129-37.

35 Tyfield LA, Stephenson A, Harvie A, Hunt L, Cockburn Clark B. Is PKU a less severe disorder in the UK? Mild mutations at the PAH gene occur frequently in England and Scotland [abstract]. Thirty-third Meeting of the Society for the Study of Inborn Errors of Metabolism, Toledo Spain. September 12-15, 1995:P011.

36 Tyfield LA, Meredith AL, Osborn MJ, Primavesi R, Chambers $T$ L Holton JB, et al. Genetic analysis of treated and untreated phenylketonuria in one family. $7 \mathrm{Med}$ Genet 1990;27:564-8.

37 Tyfield LA, Zschocke J, Stephenson A, Cockburn F, Harvie $\vec{O}$ $\mathrm{A}$, Bidwell JL, et al. Discordant phenylketonuria phenotypes in one family: the relationship between genotype and clinical outcome is a function of multiple effects. $7 \mathrm{Med}$ Genet 1995;32:867-70.

38 Ramus S, Forrest SM, Pitt DB Saleeba JA, Cotton RGH. Comparison of genotype and intellectual phenotype in untreated PKU patients. 7 Med Genet 1993;30:401-5.

39 Treacey E, Pitt J, Seller K, Thompson G, Ramus S, Cotton RGH. Phenylalanine metabolism in vivo in mild phenylketonuria, the effect of multiple loci [abstract]. Am f Hum Genet 1994;55(Suppl):262. 